\title{
REGULAÇÃO TECNOLÓGICA E JURÍDICA DAS REDES SOCIAIS (SOCIAL NETWORKS)
}

Sciiti Arata Júnior

Resumo:

Os websites de redes sociais (social networks) despertaram grande curiosidade entusiasmo do mercado brasileiro a partir do ano de 2004. São apresentadas neste estudo breves reflexões acerca da relação entre a estrutura tecnológica e termos de uso implementados e seus efeitos jurídicos, focando em temas como bancos de dados, privacidade, direito à imagem e proteção ao consumidor.

Neste estudo, não se pretende esgotar a rica discussão que envolve o tema, porém demonstrar a necessidade de ponderação tecnológica, política e jurídica ao oferecer ou aderir a um serviço de rede social.

Palavras-chave: Redes sociais. Círculos sociais. Privacidade. Personalidade. Orkut.

\begin{abstract}
:
Social network websites have drawn curiosity and enthusiasm from the Brazilian market in 2004. In this study some brief thoughts related to the relation between the technological structure and the terms of use adopted are presented, focusing on database, privacy, the right to image, and consumer protection rights.

It is not the intention to cover all issues of the rich discussion on the theme. However, it is sought to demonstrate the need for technological, political and legal thought when one seeks to offer or adhere to a social networking service.
\end{abstract}

Keywords: Social networks. Social circles. Privacy. Personality. Orkut.

1. A dramaturgia da persona

A palavra latina persona, composta pelo prefixo per (por, através) e sufixo suno (som), era usada originalmente como referência à máscura usada pêlos atores nas representações teatrais. Em seu Vocabulário Juridico, De Plácido e Silva observa a

Aluno do curso de pós-graduação com mestrado em Direito Internacional pela Faculdade de Direito da Universidade de São Paulo. 
conexãu da persona com a expressão "dramatis personac" alusão aos representantes ou personugens dramáticos. isto é, os próprios atores. '

Essa análise etimológica revela uma noção téatral relacionada à idéia de pessoa que ¿ cunstantemente explorada pelas artes e ciências humanas. Abordando a evolução histórica do conceito de pessoa humana, Fábio Konder Comparato ${ }^{2}$, identifica o estoicisıno como o primeiro marco na elaboração térica do conceito de pessoa, em que a persona teatral (o papul excrcido pêlos individuos em relaçõus sociais) é separada da issência individual de cada ser humano (que passa a ser denominada personalidad'), de modo que o papel dramático que cada um de nós representa na vida não se confunde com a individualidade pessoal.

O conceito dramaturgo às persona é também desenvolvido em The Presentation of Silf in Evervdav Life ${ }^{3}$ do sociologo canadense Erving Goffman, que defende que quando um indivíduo está na presença dc outrus, estes outros procuram obter informações a seu respeito c também trazer à discussão elementos de informação que já possuam sobre ele. A interação é vista como uma performance moldada de acordo com a audiência e ambiente social cujo script busca transmitir impressões coerentes com os objetivos dos atores. A atuação inclepende do estado mental do indivíduo de modo que a persona teatral ocorre independente de sua vontade consciente em realizar a performance.

Resumidamente, as informações nccessárias para a atuação podem ser obtidas através de duas formas: aquelas verbalmente fornecidas c aquelas expressas de modo contextual, não-verbal, não-intencional. $O$ individuo busca o controle sobre a conduta alheia no que toca à sua pessoa: esse controle é obtido por uma mudança em seu próprio comportamento de modo a transmitir uma impressão que faça com que os outros ajam de acordo com seus planos e para apresentar uma versão idealizada de si que seja mais consistente com as normas sociais, comparativamente com seu comportamento quando não está diante de uma audiência. Esse uso da persona como máscara definc o palco de uma peça de infinitos atos de falsas revelações e subterfúgios até que um determinado consenso seja atingido.

As atuações sofrem invariavelmente o efeito da segregação de audiências, de modo que performances específicas são feitas para determinadas platéias, conforme

1 Os romanos usavam o termo persona com significado geral de ser humano. independentemente de sua condição como pessoa física, sujeito de direito, ou de sua condição como escravo. objeto de direito.

2 COMPARATO, Fábio Konder. A Afirmação Histórića dor Direilos Humanos. 3. ed. São Paulo: Saraiva, 2003. p. 16.

3 Apesar de rica, esta obra não apresenta uma descriçiio completa do processo interativo. A natureza de individuos marginalizados, a importância do ritual c ccrimônia na dramaturgia e na construção de personagens é aperfeiçoada em outras obras posteriores de Ciolfman, como Stigma e Interactiun Ritual. 
suas expectativas. A espontaneidade, nesse processo, é fundamental para que não scja transmitida uma impressão artificial do comportamento.

2. Viver na verdade: a multiplicidade de opiniões

Goffman reconhece que existem diferenças culturais na representação do cu, ao reportar que membros de uma cultura anglo-americana têm a tendência de viver vidas sociais enclausuradas, interagir em ambientes determinados, manter estranhos à distância. dar aos atores uma certa privacidade para que realizem seu show c, em gcral, compartilham uma seriedade e união quanto aos dramas cívicos comuns. Estudos semelhantes são desenvolvidos nos mais diversos contextos; no Brasil merece destaque o magistral estudo sobre o povo brasileiro feito por Sćrgio Buarque de Holanda, em Raizes do Brasil, que apresenta o conceito do "homem cordial", cuja intimidade marca uma indistinção entre o público e o privado e todos são amigos em todos os lugares. ${ }^{4}$

Entretanto, independentemente destes comportamentos geralmente compartilhados em uma determinada coletividade, existe uma multiplicidade de opiniões que os individuos podem tomar diante da questão de como ser espontâneo e verdadeiro. A dificuldade da comunhão de opiniões e mesmo da mútua compreensão quando as vidas das pessoas já estão bem definidas e construidas com base em diferentes experiências é bem ilustrada em $A$ Insustentável Leveza do Ser. Milan Kundera dedica a terceira parte de sua obra para As palavras incompreendidas entre Sabina e Franz, elaborando um léxico de noções opostas sobre diversos temas, das quais a publicidade e a privacidade são assim tratadas:

\begin{abstract}
Viver na Verdade
$\dot{E}$ uma fórmula que Kafka usou em seu diário ou numa carta. Franz não se lembra bem. Está seduzido por essa fórmula. $\mathrm{O}$ que era viver na verdade'? I ma definição negativa é lácil: não mentir, não se esconder, não dissimular nada. Desde que conheceu Sahina, vive na mentira. Conversa com sua mulher sobrc congressos em Amsterdam, e conferências em Madri que jamais aconteceram. tem medo de passear com Sabina nas ruas de Genebra. Acha divertido mentir c se esconder,
\end{abstract}

\footnotetext{
As idéias de Sérgio Buarque de Holanda contribuem tambím para a comprcensão do grande sucesso de software sociais intre brasileiros, como o Fotolog, Orkut. Multiply, entre outros, cujas estatisticas demonstram que o Brasil lidera em quantidade de usuários cadastrados. A análise cultural também explica a menor preocupação do ordenamento juridico brasileiro com questôes ligadas á privacidade e liberdade de expressão, que ganham cunho mais severo nos Estados Unidos da América. Apesar das diferenças entre os sistemas juridicos, ialemo-nos no presente estudo da doutrina e experiència americana na definição da problemática relacionada à privacidade e soluções propostas, com as devidas ressalvas na análise do Dircito Comparado.
} 
justamente porque nunca o fez antes. Sente o prazer de um primeiro da classe que decide um dia. finalmente, cabular.

Para Sabina, viver na verdade, não mentir nem para si nem para os outros, só é possivel se vivirmos sem público. Havendo uma única testemunha de nossos atos, adaptamonos de um jeito ou de outro aos olhos que nos observam, e nada mais do que fazemos é verdadeiro. Ter um público, pensar num público, é viver na mentira. Sabina despreza a literatura em que o autor revela toda a sua intimidade, e também a de seus amigos. Quem perde sua intimidade perde tudo, pensa Sabina. E quem a ela renuncia conscientemente é um monstro. Por isso. Sabina não sofre por ter que esconder seu amor. Ao contrário, para cla esta i a única forma de viver 'na verdade'

Quanto a Franz., está convencido de que na separação da vida em domínio privado c em domínio público está a fonte de toda mentira: a gente é uma pessoa em particular e outra em público. Para Franz, viver 'na verdade' é abolir a barreira entre o privado e o público. Mencionava com prazer a frase de André Breton em que ele dizia que gostaria de viver "numa casa de vidro' onde nada é scigredo e que está aberta a todos os ollares.

Através de seus personagens, Kundera trabalha uma de suas principais preocupações, a luta pela defesa de seu direito à vida íntima. Para ele existe uma fronteira mística entre a vida intima e a pública que não se pode atravessar impunemente. ${ }^{6}$

\section{Enfraquecimento da fronteira entre o público e o privado}

A divisão entre a vida pública e a privada, porém, cada vez torna-se mais tênue conforme são difusas as novas tecnologias de computação c as inovações multimídia de comunicação que aumentam as conexões entre locais e pessoas que estavam anteriormente isolados. num processo de virtualização. ${ }^{7}$ Como resultado. o

5 KUNDERA, Milan. A Insustentável Leveza do Ser. Tradução Teresa Bulhōes Carvalho da Fonseca. São Paulo: Companhia das Letras, 1999. p. 133.

6 Em Testaments Betrayed: An Essay in Nine Parts, London, Faber, 1995, Milan Kundera diz que apenas um hipócrita afirmaria que, por inexistir tal fronteira, vive a mesma pessoa tanto na vida pública como na intima. Aqueles que assim o fazem seriam monstruosos, acabando por abdicar de espontaneidade na sua vida intima e agindo de modo irresponsável na vida pública. Kundera posiciona-se de modo diametralmente oposto a Kant, para quem o mal é, por definição, secreto e que o moral é aquilo que é apto a ser visto, de modo que a moralidade se traduz exatamente na coincidència entre o público e o privado.

I.ÉVY. Pierre. O que é o Virlual? 1. ed. São Paulo: I:d. 34. 1996, define o processo de virtualização como uma "heterogênese, um devir outro. processo de acolhimento da alteridade", sendo que o "virtual" não é oposto a "real" O "virtual" está oposto ao "atual": enquanto a atualização é a solução de um problema não anunciado, uma produção de nuvas qualidades, a viriualizaçào i seu movimento inverso, uma "elevação à potència" da entidade considerada. 
indivíduo já não mais pode confiar em seus sentidos na determinação de que tipo de ambiente ele se encontra para o uso da persona como a máscara de Goffman. ${ }^{3}$ Ademais, o indivíduo perdeu significativa parte de seu controle sobre a noção de estar sendo observado, ouvido e mesmo filmado. O espaço físico percebido ao redor do indivíduo não é mais um indicador dos locais ou pessoas que possam estar a ele conexos. Assim. locais que parecem privados, podem ser públicus.

A fixação da fronteira entre o público e o privado dentro de uma perspectiva liberal para compatibilizar a liberdade de mercado, o controle da informação e a proteção da privacidade é o paradoxo da liberdade, ${ }^{9}$ de difícil equilibrio.

Hannah Arendt discorre com detalhes o surgimento e evoluçăo dos conceitos de "público" e "privado" indicando que o individualismo moderno contribui para o enriquecimento da esfera privada que, inicialmente, indicava que o indivíduo assim estaria privado das mais dignas capacidades do homem que eram exercidas nos negócios da res publica. Existem algumas informações que devem ser ocultadas e outras que devem ser expostas em público para que possam adquirir alguma forma de existência. Para ela a distinção é necessária pois somente longe da luz do espaço público a vida intima é possível.

Quando as duas esferas são claramente distintas, é possivel comportar-se conforme as expectativas e necessidades sociais. Quando as esferas se entrelaçam, ${ }^{10}$ isso lica mais difícil e existe uma tendência à retração comportamental e menor interação social ou então em um comportamento inconseqüente e sujeito a erros não seriam cometidos se os indivíduos estivessem em um ambiente mais claro.

\footnotetext{
O tema da construção da subjetividade è tratado por inúmeros teóricos que dedicaram estudos sobre este complexo assunto. Goffman i cscolhido para o presente estudo como o autor mais apropriado para identificar a problemática da harmunização das relações em redes sociais que conectam diversos circulos sociais. Para referências em outras sciaras da subjetividade, pode-se recorrer a Rení Descartes, Jean-Jacques Rousseau, Michel Foucault, Gilles Deleuze, David Hume, Lev Vygotsky, Mikhail Bakhtin, Anthony Giddens, George Berkeley, entre outros.

9 MACEDO JR., Ronaldo Porto. Privacidade. Mercado c Informaçào. Revista de Direito do C'onsumidor, São Paulo, n. 31, p. 17, jul./set. 1999.

10 Ou mesmo quando o espaço público deixa de ser geograficamente definido (como era a Agora ateniense) e a pauta dos debates passa a ser definida pela midia. Maiores considerações sobre as transformações do espaço público são desenvolvidas por Habermas em A Transformaçâo Estrutural da Esfera Pública. Celso Lafer, em A Reconstrução dos Direitos Humanos: um diálogo com o pensamento de Hannah Arendı. São Paulo, Companhia das Letras, 2001, aponta para a crescente interferência na tsfera da vida privada por parte do poder público e uma maior possibiliciade de terceiros se intrometerem no àmbito da intimidade das pessoas. Observa-se que não se trata de um fenômeno de uma via apenas: a discussão c exposição das intimidades ao domínio público trivializam a bisbilhotice e banalizam o público.
} 


\section{Círculos sociais}

Paralela e complementarmente à visão dual público/privado. para compreender os fenômenos sociais é útil a identificação de círculos sociais, nos quais determinadas informações sobre o indivíduo podem estar mais públicas do que outras. Cada um dos círculos sociais compartilha, genericamente, de um ponto de vista de nossa individualidade projetada. A multiplicidade de círculos sociais é assim tratada por Pontes de Miranda:

O fato social é a relação de adaptação (ato, combinação, fórmula) do indivíduo à vida social. a uma. duas ou mais coletividades (círculos sociais) de que faça parte, ou dessas aos indivíduos, entre si. Tais círculos, pré-histórica e historicamente, foram o par. o clã, a fratria, a família, a tribo, a nação de tribos, etc. Na mesma época, podem ser, quanto à extensão: o par sexual, a amizade, a família, a escola, a classe social, o partido. o bairro, o Município, o Estadomembro, o Estado, etc. ${ }^{11}$

Sobre o tratamento jurídico dessa multiplicidade de círculos sociais, o clássico autor aponta que em tempos de evolução social é necessária uma referência à sociologia, em particular à lei da crescente dilatação e integração dos círculos sociais.

\section{Integrando os círculos sociais: as redes}

$\Lambda s$ redes sociais são formadas por grupos de pessoas conectadas através de distintas formas e graus de familiaridade. Têm sido objeto de numerosos estudos de sociologia e antropologia. Seu estudo matemático é feito através da teoria dos grafos, que representa objetos através de vértices e elos que possibilitam atribuir valores quantitativos às redes sociais e assim melhor interpretar como os indivíduos interagem em situações complexas, como epidemias virais, organizações terroristas e contatos potenciais para o sucesso profissional. Através de sistemas de reputação que podem ser construidos a partir de redes sociais. é também vislumbrada uma solução técnica para melhor filtragem de spam. $^{12}$ Apesar da utilidade das diversas aplicações práticas com finalidade de aperfeiçoamento de mercado e redução de custos de transação, sua utilização deve ter em mente os riscos de violações ao direito à privacidade, direito à imagem e abusos na manipulação de bancos de dados, entre outros que serão brevemente abordados neste estudo.

1 MIR NNDA, Francisco Cavalcanti Pontes de. Tratado de Direito de Familia. 3. ed. São Paulo: Max Limonad, 1947. p. 37.

12 GOLBECK, Jennifer. Reputation Nenvork Analysișfor Email Filııing. Disponivel em: $<$ http://www.mindswap.org/papers/Email04.pdf $>$. 
As redes, quando bem utilizadas, permitem que o homem alcance objetivos antes remotos ${ }^{13}$ e otimize as suas relações de oferta e demanda. Nesse sentido, é extremamente positiva para a efetivação da Declaração de Princípios e do Plano de Ação traçados pela Cúpula Mundial sobre a Sociedade da Informação. ${ }^{14}$ Como toda tecnologia, porém, os seus usuários devem ser suficientemente educados para utilizar as novas ferramentas da melhor forma possível e evitar situações que possam implicar em riscos morais e patrimoniais.

\section{As redes sociais no ciberespaço}

Através da Internet as redes sociais ganham eficiência e possibilitam diversas aplicações pela facilidade em cruzamento de bancos de dados. Tornaram-se uma grande sensação a partir de 2003 com a popularidade de certos websites. ${ }^{15}$ Assim como os primeiros estudos feitos sobre o ciberespaço freqüentemente faziam referência à obra Neuromancer do uscritor de ficção cyberpunk William Gibson, os recentes escritos feitos acerca das redes sociais na Internet fazem invariavelmente alusão à expressão "seis graus de separação" 16 associada ao Small World Experiment de Stanley Milgram, que mostra que os círculos sociais estão muito próximos uns dos outros e muitas vezes com amplas áreas de intersecção. Deste modo. a atuação da persona deve, cada vez mais, adequar-se a mais de uma platéia simultaneamente.

Apesar do sucesso em angariar grande número de usuários utilizando marketing viral e interface popular, conectando os indivíduos a seus diversos círculos sociais, é possivel defender que as redes sociais não são inovadoras, ${ }^{17}$ pois, desde os primórdios da comunicação digital em rede, diferentes plataformas foram disponibilizadas

13 As redes de movimentos sociais, por exemplo, potencializam a força discurso político e de articulação "entre o local e o global, entre o particular e o universal, entre o uno e o diverso. nas interconexõcs das identidades dos atores com o pluralismo", observa Use Scherer-Warren em Redes de Movimentos Sociais. São Paulo, Ediçōes Loyola, 1993, p. 10.

14 www.itu.inu/wsis!

Is Segundo matiria de PESCOVITZ, David. The Technology of the Year: Social Network Applications. Business 2.0. San Francisco. v. 4, n. 10. p. 113. nov. 2003., dentre os projetos mais populares pode-se destacar o SixDegrees.com, fundado $\mathrm{cm} 1997$ e com atividades encerradas $\mathrm{cm}$ 2000. Posteriormente, Ryze, eCademy, Spoke Software e Linkedln para networking profissional, Firiendster com foco em relacionamentos romànticos, Visible Path focado em comércio, e Tribenet e Orkut, versöes beta, congregando distintos usos simultâne ss. No Brasil, destaca-se o $1^{\circ}$ Grau.

Postulado de que qualquer indivíduo estaria conectado a qualquer outro no mundo através de uma pequena sequiência (seis intermediários) de conhecidos. o que i parcialmente explicado pela existencia de hubs, pessoas que têm uma vasta rede de contatos e aproximam diferentes grupos.

17. O professor da Niw York University. Clay Shirky, inclui em sua definição de software social todo o tipo de softu'are que permita comunicaçào coletiva, desde o campo "c.c." no email até vastos mundos virtuais como o de EverQuest, podendo ser não-direcionados como uma sala de bate papo ou visando uma determinada tarefa, como um wiki. Vide http://www.shirky.com/writings/group_politics.htm! 
para relacionamentos, seja através dos bulletin board services, Usenet, multi-user dungeons, internet relay chat, WELL, usenet, home pages, websites de serviços de recolocação profissional, namoros, fóruns de discussão diversos, weblogs, fotologs, wikis... de modo que a nova geração de redes sociais não é arauto do conceito de social software.

Independente dos questionamentos que possam ser feitos acerca da novidade na técnica de comunicação, é fato que as redes sociais na Internet conquistaram popularidade a partir de 2003. São tecnologias pautadas por uma série de valores e conseqüências, algumas previstas e outras inesperadas. $E^{\prime}$ o primeiro princípio do tecnorrealismo: ${ }^{18}$ tecnologias não são neutras. Cada um destes possui valores diferentes, e devem atentar para determinados riscos jurídicos, principalmente aqueles advindos das novas formas de interação social acima descritas. Cada um dos meios de comunicação é reflexo de uma tecnologia sendo adaptada para permitir uma interação social e uma apresentação do eu social e consciente.

O meio pelo qual os indivíduos se conectam digitalmente é, porém, tão distinto do mundo físico que os comportamentos sociais tendem a ser diferentes: a tecnologia não apenas conecta as pessoas, mas define como elas interagem. O meio é a mensagem. Assim, cumpre analisar como cada manifestação de rede social lida com a rrágil redoma da intimidade. Cada uma delas é pautada com diferentes valores e objetivos. Nesse sentido, Paul Heyman, em Distributed Social Network Protocol diz que a informação fornecida nas redes sociais varia conforme a premissa do serviço oferecido. Heyman classifica algumas redes sociais que implicitamente postulam que os amigos de amigos podem ser potenciais amigos ou parceiros românticos, e outros que postulam que os amigos de amigos são mais tendenciosos da dar confiança ao indivíduo. facilitando sua inserção profissional.

A escolha em focar em um determinado círculo social é meramente opção tecnológica e estratégica do plano de negócios daquele que disponibiliza os serviços de uma rede social. Existem projetos que integram diversos círculos simultaneamente. Isso pode tanto estimular contatos não-óbvios (colegas de trabalho deparando-se com informações acerca da intimidade tradicionalmente familiar) como também gerar conflitos, pois as informações que a persona busca representar não encontram mais os limites tradicionais e são distribuídas a todos os membros de todos os círculos sociais indistintamente.

www.technorealism.org 


\section{Code is law}

Considerando-se que as tecnologias implicam sempre em uma série de efeitos, tanto positivos quanto negativos, ${ }^{19}$ é fundamental analisar quais são os valores que orientam uma determinada tecnologia para a análise dos efeitos que esta pode causar através de sua adoção. Lawrence Lessig, em Code and Other Laws of Cyberspace, lidera forte corrente doutrinária próxima da Teoria Tridimensional do Direito, de Miguel Reale, que postula que o "Direito é uma integração normativa de fatos segundo valores" ${ }^{20} \mathrm{~A}$ teoria Code is Law de Lessig dá forte ênfase a essa dimensão tecnológica (fática) pela sua força regulatória que interage com a força jurídica.

Valendo-se de observações de David Chaum, Philip Agre $^{21}$ relata que registros de dados não podem causar problemas de privacidade se a base tecnológica nãopermitir sua atribuição aos individuos cujas vidas representam. Caso os bancos de dados identifiquem os indivíduos através de métodos universais como nome ou número de documento de identidade, os dados podem ser facilmente propagados e cruzados, e assim empregados para finalidades secundárias em detrimento do indivíduo. Assim, Chaum apresenta a abordagem alternativa de empregar pseudônimos digitais. Entretanto, a coleta de dados de uma rede social verdadeira ${ }^{22}$ é justamente oposta à de um sistema que protege a privacidade usando pseudônimos.

A inexistência de um sistema seguro permite, tecnologicamente, que dados falsos sejam lançados ao sistema, encontra-se, desde as primeiras manifestações de comunicações digitais, homens passando-se por mulheres, crianças por adultos, em uma insegurança de comunicação que ficou marcada pela frase "Na Internet ninguém sabe que

19 A esse respeito, vide intróito de Technopoly: The Surrender of Culture to Technology, de Neil Posiman.

20 Reale reconhece que no processo de regulação existem três vértices: fato, valor e norma, enquanto Lessig identifica um quarto vértice, mercado, que pode ser compreendido como uma manifestação fática. Assim, as decisões comportamentais ponderam a influência exercida por cada um destes vértices. de modo a prosseguir ou abster-se de determinada atitude. Além de atuar diretamente sobre os individuos, essas dimensões interagem mutuamente umas sobre as outras. Um exemplo é a campanlia de combate ao fumo, que utiliza a força da lei para impor figuras que desestimulam o tabagismo nas caixas de cigarros, criando assim uma força valorativa. Limites legais também são impostos aos niveis de tabaco c nicotina de modo a evitar un vicio quimico, vetor fático.

$?$ AGRE, Philip. Beyond the Mirrar World, m: Technology and Privacy: The New Landscape. London: The MIT Press, 1998. p. 52.

22 Para o presente estudo, utiliza-se a expressão "rede social verdadeira" como referência àquela que se vale dos dados pessoais e verdadeiros dos seus usuários para permitir a interação através de afinidade de interesses e relacionamentos já existentes no mundo material. Essas redes buscam, contratual e tecnologicamente, evitar que informações falsas ou parciais sejam alimentadas ao sistema, pois causam ruido e prejudicam sua operação otimizada. É, porém, tecnicamente possivel a existência de outros modelos de redes sociais que utilizam como base primordial as personalidades ficlicias, como aquelas destinadas a roleplaying games como o Multi-User Dungeon. Redes sociais voltadas a relacionamentos amorosos, por sua vez, estimulam uma combinação: utiliza-se o heterônimo para o contato inicial, que assegura uma maior privacidade e somente em um segundo momento o homônimo é revelado conforme os usuários julguem conveniente. A distinção entre "verdadeiro" e "falso", porém, é controversa, sendo utilizada neste estudo de modo vulgar, sem qualquer reflexão filosófica. 
você é um cachorro" "23 As redes sociais verdadeiras são prejudicadas pela ausência de sistemas seguros que não permitem evitar que falsos perfis sejam inseridos, rupresuntando personagens de ficção literária, cinematográfica ou mesmo pessoas reais diferente; daquelas que criaram o perfil virtual. Os falsos perfis permitem aplicações inovadoras, ${ }^{24}$ porém apresentam riscos de infração à propriedade intelectual. calúnia, difamação, injúria, falsidade ideológica. entre outras infrações jurídicas que diminuem a confiança no sistema e portanto seu funcionamento otimizado.

Observa-se que parte dos problemas encontrados nas interações em redes sociais verdadeiras ocorre pelas diferentes expectativas que cada um dos usuários tem sobre o sistema, o que é reduzido em casos de redes sociais que utilizam pseudônimos ou são focadas para determinadas aplicações, como os jogos interativos, namoros, busca de cmprego... ¿ assim evitam a colisão de diferentes círculos sociais. Para lidar com as múltiplas necessidades e expectativas dos usuários de uma rede social verdadeira, além das forças éticas, jurídicas e mercadológicas, é necessária a construção de uma arquitetura tecnológica de comunicação que possibilite maior controle aos usuários.

Essa escolha tecnológica deve estudar que efeitos são obtidos através da infra-estrutura e da interface do serviço oferecido. Ilustra essa relação a preocupação quanto à interface a discussão acerca de controle de recebimento de e-mails publicitários: dependendo do padrão utilizado no preenchimento de um cadastro, existe maior tendência dos usuários a aceitarem ou rejeitarem a oferta de envio de mensagens publicitárias em seu e-mail. Durante as discussões sobre a regulação (tanto a auto-regulação como a regulação jurídica) houve defensores para um padrão em que para que o usuário recebesse as mensagens de marketing direto, ele deveria necessariamente clicar em uma checkbox confirmando sua aceitação. Essa alternativa resulta em menos aceitações do que a inversa: pressupor a aceitação do usuário, que deve clicar na checkbox para não receber as mensagens. Cada uma das alternativas representa um valor diferente quanto à facilidade ou dificuldade da manifestação de vontade do usuário em controlar o recebimento de mensagens.

Adicionalmente, a tecnologia tem papel fundamental no processo de virtualização que dificulta a percepção dos indivíduos em saber se estão em um ambiente público ou privado e, portanto, determinar como moderar sua exposição e expectativa de

23 "On the Internet. nobody knows you are a dog", legenda de uma charge que ilustrava dois cies conversando na frente de um computador. publicada no The New Yorker de 05.07.1993, por Peter Steiner.

24 Por excmplo. alguns estúdios de c:nema vêm experimentando estratégias de divulgação pela criação de perfis de personagens de seus tilmes em redes sociais.Vide mais em Daniel Terdiman. Friendster's Fakester Buddies. WiredNews. Disponivel em:

<http://www.wired.eom/news/culture/0,1284,64156,00.html?ww=newsletter_topstories_html>. 
privacidade: Victoria Bellotti, analisando a arquitetura de comunicação, aponta dois fenômenos que influem no controle de fluxo de informações, e, portanto, no gerenciamento de privacidade: desincorporação e dissociaçao. ${ }^{25}$

Desincorporação ocorre quando os recursos de comunicação não permitem que a apresentação pessoal seja tão efetiva quanto em um ambiente cara a cara. A representação em uma chat room pode ser limitada apenas a palavras, smileys e eventual foto estática ${ }^{26}$ do avatar. A desincorporação também significa que o comunicante pode estar inconsciente acerca da quantidade de informações que está transmitindo publicamente, por uma falta de feedhack da arquitetura de comunicação. Alguns sistemas de rede social permitem que o usuário tenha um controle ex post de quem obtém suas informações, valendo-se de um registro de todos os usuários que obtiveram acesso ao seu perfil. Outros, mais zelosos com a necessidade de controle, usam políticas ex ante de modo que apenas revelam informações pessoais a outros usuários do sistema mediante prévia e expressa autorização do indivíduo. Outros, ainda, revelam qualquer informação a qualquer usuário, sem manter qualquer registro (ou apenas quanto ao número de usuários que obteve acesso a seu perfil) ou selecionam algumas informações que têm caráter mais sensivel apenas a determinados grupos de pessoas - sendo, assim, necessário que os usuários classifiquem seus contatos em diferentes categorias, conforme o grau de intimidade ou círculo social a que fazem parte, dependendo, portanto, de uma rotulagem que pode ser aproximada ou refinada conforme a tecnologia adotada. Um dos efeitos da desincorporação é uma maior tendência à bisbilhotagem quando a estrutura de comunicação permite que eu observe o comportamento alheio sem ser observado.

Dissociação é identificada quando uma pessoa remota não possui qualquer presença detectável. Os resultados das ações são compartilhados mas os atores em si são invisíveis ou os atos não são atribuiveis a determinado ator. Não se pode determinar quem está fazendo determinada ação ou quem fez o quê. Assim, pela dissociação as pessoas remotamente conectadas e suas respectivas ações são dificeis de detectar ou identificar. A possibilidade de completa dissociação é relativa quando usadas técnicas de computer forensics e investigação. Entretanto, para a maior parte dos usuários, a escolha entre um ou outro padrão tecnológico influencia no grau de dissociação.

25 BELLOTTI, Victoria. Designfor Privacy in Mulfimedia Computing and Communications Environments. In: AGRE, Philip; ROTEMBERG, Marc (Org.). Tecnhology and Privacy: The New Landscape. London: The MIT Press, 1998. p. 74

26 Sobre a importância do contato visual com o rosto $\mathrm{mm}$ interações mediadas por sistemas de comunicação. vide Mediated Faces. de Judith Donath. Disponivel em:

$<$ http://sing.media.mit.edu/papers/Donath/MediatedFaces/MediatedFaces.CT2001.pdf. 
Tanto a desincorporação como a dissociação podem ser reduzidas através da implementação de um retorno maior sobre as informações pessoais que são capturadas e projetadas por usuários da rede social. Os usuários devem dispor de meios técnicos para controlar suas informações pessoais. Bellotti aponta alguns princípios a serem seguidos e boas práticas necessárias para resgatar a consciência que pode ser perdida na virtualização: podemos não mais saber que tipo de informação estamos transmitido, como ela se parece, quão permanente ela é, a quem é transmitida e quais podem ser os limites daqueles que pretendem utilizá-la.

Paralelamente à decisão sobre a base tecnológica que orientará os limites fáticos sobrc o que se pode ou-não fazer em uma rede social, é necessário refletir sobre aspectos mercadológicos, éticos, e sobretudo juridicos na elaboração das políticas de uso da rede social.

A título exemplificativo, tomemos o famoso acrônimo Yoyow, que representava os mais fundamentais valores da Well: "You own your own words":" Através de mecanismo contratual, os usuários assumem a responsabilidade jurídica ${ }^{28} \mathrm{e}$ ética pêlos seus escritos e pelas imagens e arquivos disponibilizados, através dos serviços de uma rede social. Os usuários são responsáveis em respeitar direitos de terceiros, incluindo os de propriedade in electual. privacidade, de não caluniar outros membros. enfim. de comportar-se de acordo com padrões éticos e legais. Outro efeito da política Yoyow é que todo o conteúdo publicado pela Well continua a ser direito patrimonial de seus autores, a não ser na hipótese de sua expressa renúncia. Assim, accitando a propriedade pelas próprias palavras, seus interlocutores são impactados pela maior responsabilidade quanto às suas conseqüências. Ainda, o usuário tem o direito de remover seus trabalhos da Well a qualquer tempo.

Essa propriedade contratual assegurada pela rede social decerto não se sobrepõe à liberdade de expressão e aos limites do direito autoral, de modo que continua sendo possível, dentro do razoável, fazer citação de comentários publicados em um fórum da Well independentemente da autorização prévia do seu locutor. ${ }^{29}$ Entretanto. o oposto não é necessariamente verdadeiro: se, ao invés da política Yoyow, a rede social contratualmente retivesse para si, com exclusividade, todos os direitos sobre todas as formas de expressão manifestas através de seu sistema, a regra geral é que seria

27 www.well.com/member_agreement.html

28 Será oportunamente analisado que a limitação de responsabilidade através de instrumento particular $\dot{c}$ relativa no direito brasileiro.

29 WHIT TLE, David. Cyberspace: the Human Dimension. 1. ed. New York: H. II. Freeman and Company. 1997. p. 248 
juridicamente impossível utilizar qualquer material que tenha ali sido publicado sem uma licença prévia dos representantes legais da rede social.

Ademais, ${ }^{30}$ essa hipotética politica daria à rede social a capacidade jurídica (que, por sua vez, legitimaria a implementação de mecanismo para a possibilidade técnica) de restaurar qualquer conteúdo ali publicado, de modo a preservar o trabalho coletivo. Essa alternativa desperta, por um lado, legítimas preocupações quanto ao direito moral de autor de retirada de circulação previsto no art. 24. VI, da Lei de Direitos Autorais, Lei n. 19.610, de 19.02.1998. Se, por outro lado, não existe qualquer garantia de que as contribuições em discussões de fóruns não serão apagadas pelos usuários, é possível deparar-se com tamanho suicídio digital ${ }^{31}$ coletivo que torne sua leitura incompreensivel. Uma abordagem tecnológica para o problema de corrupção do conteúdo é o self-help que mantém um histórico de tudo o que fora anteriormente publicado. possibilitando a restauração, como um wiki.

Reconhecidas as forças tecnológica e jurídica ${ }^{32}$ é necessário combiná-las de forma harmoniosa para efetivar os valores buscados pela rede social.

\section{Bancos de dados: proteções e responsabilidade}

A estrutura de uma rede social é oferecida aos seus usuários, que alimentam o sistema basicamente de dois modos: informações pessoais em seus perfís e mensagens publicadas em fóruns de discussão. Tanto essas informações diretamente produzidas pelos usuários como as estatísticas de medição do sistema, realizadas pelos administradores da rede social. compõem um de seus maiores valores: um banco de dados que deve ser

30 Inúmeros outros questionamentos relacionados à propriedade intelectual podem ser apresentados. como os conflitos que podem surgir entre a politica de uso da rede social e eventuais acordos firmados entre empregado e empregador em que a produção intelectual do primeiro é translerida ao último, limites aofair use. os debates em torno dos hate sites... A intenção deste estudo ć discutir apenas alguns dos aspectos juridicos das redes sociais para despertar a atenção para a importància da harmonização entre as normas juridicas legais e contratuais com a tecnologia e valores sociais de modo a minimizar os riscos jurídicos de operação e uso de uma rede social.

31 Blair Newinan, após vários anos de participação on-line com demais colegas da WELL, decidiu apagar todos os seus comentários escritos ra rede. Sua atitude despertou indagações a ruspeito do trauma gerado por uma rasura em massa. como um suicidio intelectual, que precedeu seu suicidio fisico semanas depois. $\mathrm{O}$ suicidio virtual de Blair foi facilitado por um software disponibilizado por um dos técnicos da WELL que passou a ser utilizado com tamanha freqüência em alguns fóruns "faltava tanta coisa que se tornou desesperadamentc impossivel seguir o fio à meada", conforme relata Howard Rheingold em A (omunidade Virlual.

32 Os valores éticos e sociais e as forças de mercado apontados por Lessig em Code and Other Laws of Cyberspace não são abordados neste estudo. 
protegido juridicamente. Assim, é necessária a distinção entre a base de dados e o sistema de administração desta base. ${ }^{33}$

A proibição contratual de realização de spidering, técnica visando a captura de dados, não é suficiente para proteger o titular do banco de dados e os indivíduos cujos dados compõem a base de dados. Uma vez capturadas as informações, não há volta, dada sua volatilidade e facilidade de reprodução, principalmente quando nenhuma tecnologia de digital rights management é utilizada. É necessário lidar com expectativas dos usuários que. ao depositar informações em uma rede social, não desejam que estas sejam capturadas ou repassadas a terceiros, fora da rede social.

A Lei de Direitos Autorais, em seu art. $7^{\circ}$ arrola, dentre as obras intelectuais protegidas, as bases de dados e outras obras que, por sua seleção, organização ou disposição de seu conteúdo, constituam criação intelectual. Entretanto, referida proteção é quanto à base de dados como um todo e não quanto a cada item de informação individual.

O art. 87 da Lei de Direitos Autorais dispõe ainda: "O titular do direito patrimonial sobre uma base dados terá o direito exclusivo, a respeito da forma de expressão da estrutura da referida hase, de autorizar ou proibir: (i) sua reprodução total ou parcial, por qualquer meio ou processo, (ii) sua tradução, adaptação, reordenação ou qualquer outra modificação, (iii) a distribuição do original ou cópias da base de dados ou a sua comunicação ao público, (iv) a reprodução, distribuição ou a sua comunicação ao público dos resultados das operações mencionadas no inciso II deste artigo" O Direito brasileiro, ${ }^{34}$ assim, boas proteções contra abusos cometidos contratos titulares de bancos de dados, atendidos os requisitos de criatividade e originalidade. ${ }^{35}$ Os empreendedores que envidam esforços em construir sistemas inovadores de redes sociais podem garantir a proteção de seus ativos contra concorrentes que busquem aproveitar de bancos de dados já existentes.

Para que possa minimizar sua exposição a infrações por publicar material protegido por direitos autorais, a rede social pode obter as devidas licenças através dos termos de uso. Entretanto podem surgir problemas quando o usuário da rede que veicula o

33 Clovis Silveira, em Bancos de Dados Originais e Não-Originais, esclarece que o sistema de administração de base de dados é soffsware utilizado para efetuar o armazenamento, a recuperação e o tratamento dos dados de uma determinada base de dados.

$\therefore$ Sobre proteções no direito norte-americano, vide artigo de KEUNECKE, Karla. Das Bases de Dados Proteção Juridica no Âmbito da Propriedade Intelectual. Revista da Associação Brasileira da Propriedade Intelectual, São Paulo, n. 57. p. 48-55, mar.-abr. 2002.

35 Clovis Silveira (op. cit.) aponta para estudos em que, analisadas propostas de proteçào tambèm das bases de dados desprovidas do caráter de uriginalidade, os custos para acesso à informação aumentariam e assim o acesso à informação encarecuria. 
conteúdo não tem legitimidade para autorizar a rede social, sendo nula a pretensa autorização obtida através dos turmos de uso.

Aquele que oferece os serviços de uma rede social deve, assim, estar precavido com as ações cometidas atravćs de seu intermédio. Observa-se atualmente uma tendência de atribuição de responsabilidade ao prestador de serviços sobre o conteúdo das discussões, perfis de usuários e toda forma de informação publicada diretamente ou através de hyperlink a informações hospedadas fora do sistema da rede social.

Uma analogia pode ser feita com o caso dos "leilões virtuais" em operação no Brasil. apesar de ser muito controverso o posicionamento dos tribunais: existem decisões no sentido de que referidos websites apenas atuam como um classificado, divulgando relações as quais não possui qualquer vínculo ou responsabilidade ${ }^{3 t t} \mathrm{e}$, de outro lado, decisões que, entendendo haver comissão paga quando o negócio se aperfeiçoa, o website atua como intermediário e portanto sujeito à responsabilidade solidária nos termos do Parágrafo único art. $7^{\circ}$ do (ódigo de Defesa do Consumidor, ${ }^{3,}$ Lei n. 8.078, de 11.09.1990.

A responsabilidade dos websites em caso de transações de produtos que infrinjam direitos de terceiros implicaria na necessidade de um controle prévio a cada informação divulgada por seus sistemas. ${ }^{\text {?s }}$ Isso imporia uma onerosa obrigação de monitoramento prévio do conteúclo publicado desses serviços para evitar a responsabilidade solidária em virtude do art. 186 do Código Civil, Lei n. 10.406, de 10.01.2002.

F.m vista da inexistência de legislação especifica sobre o assunto e dos controversos posicionamentos dos casos julgados até o momento, é prudente a implementação de mecanismos tecnológicos e contratuais para resguardar os interesses das partes envolvidas e reduzir o risco de imputação de responsabilidade por mau uso dos sistemas de rede social.

Estudo feito pelo Comitê Jurídico da Câmara Brasileira de Comércio Eletrônico, em 13 de abril de $2004,{ }^{39}$ ressaltou que existem riscos de responsabilidade para os websites principalmente se estes forem coniventes com situação de fraude e se receberem comissão pela intermediação. De outro lado, se figuram como um mero

36 Vide, por exemplo, Procisso nfjECOS-1 $-0489 / 2003$ do $5^{\circ}$ Juizado Cível de Aracaju e Recurso 2003.700.006915-1 da Primeira Turma Recursal do Consclho Recursal dos Juizados Especiais (iveis c Criminais da Comarca da Capital do Estado do Rio de Janeiro.

37 Processo n!2003.03.1.014088-5 do Juizado Especial/DF.

38 http://www.terra.com.br/istoedinheiro/346/ecommerce/346 leilao pirata.htm

39 http://www.camara-c.net/_upload/Ata_13_04_04.pdr 
classificado, sem qualquer relação com os anunciantes, os argumentos para sua isenção de responsabilidade tornam-se mais fortes, exceto nos casos de dolo e culpa.

Algumas redes sociais possuem regras de repressão a comportamentos indesejados, que podem ser sutis como ranking feito pela comunidade de usuários buscando estabelecer um sistema de reputações que afeta a projeção da personalidade dos usuários, até outros métodos como a eliminação de perfis cadastrados ou sua suspensão temporária. Apesar da plasticidade da analogia desta repreensão a uma prisão digital, por restringir a liberdade do indivíduo dentro da rede social, não é juridicamente possível o aproveitamento da analogia para a outorga de habeas corpus em tais situações. ${ }^{40}$ Entretanto, mediante percepção de dano decorrente da impossibilidade de celebrar tempestivamente qualquer ato jurídico através da rede social, pode o usuário ter legítima expectativa de reparação.

Mais uma questão a ser enfrentada pelos arquitetos das redes sociais ¿́ como proceder no caso de falecimento, no mundo físico, do usuário que possui cadastro na rede social. Deve ser indicado, junto a suas informações pessoais, o estado de falecido? Caso contrário, será necessário lidar com eventuais terceiros induzidos em erro. Em redes sociais verdadeiras, o perfil de um usuário apresenta uma natureza jurídica pessoal e intransferível, não constituindo patrimônio a ser partilhado ou negociado.

Em redes sociais verdadeiras, essas questões estão intimamente ligadas à importância e risco em promover certificação dos usuários. A segurança e a privacidade estão intimamente ligadas, pois por um lado o sistema deve ser seguro de modo a não permitir que terceiros de má-fé possam obter acesso a dados pessoais. enquanto, de outro lado, as informações que são fornecidas a um banco de dados de uma rede social devem ter credibilidade, caso contrário é possivel a criação de perfis personificando terceiros, celebridades ou não, com propósitos jocosos ou mesmo visando fraude. O problema que se apresenta é que quanto maiores as medidas para a certificação dos dados (p.ex. solicitação de comprovante de residência, número de cartão de crédito, comparecimento pessoal em estabelecimento da empresa que disponibiliza a rede social, ou outros meios de comprovação), maior é a confiança depositada no sistema e, assim, maiores os prejuízos que podem ocorrer no caso de um roubo de identidade.

40 A respeito, vide Liberdade Virmal: Juiz indefere HC para garantir locomoção no ciberespaço, por Umar Kaminski. http://conjur.uol.com.br/textos/16887/ 
9. O equilibrio da privacidade

Apesar de árdua, a definição de privacidade é necessária para que o Direito possa lidar com violações identificadas. Etimologicamente, privacidade significa privar, separar, alusão ao distanciamento das coisas públicas. Em termos práticos, não ć o "direito de ser deixado em paz" nem tampouco o "direito a uma personalidade

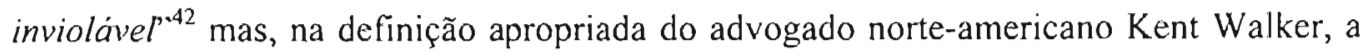
capacidade de evitar que terceiros utilizem, armazenem, compartilhem informações sobre o indivíduo. Alan Westin, por sua vez, define a privacidade de informação como "o direito de individuos, grupos ou instituições para determinar por si quando, como e em que proporção informação a seu respeito é comunicada a terceiros"

O controle sobre a informação pessoal é o controle sobre a personalidade projetada ao mundo, de modo que o direito à privacidade é a liberdade contra limitações arrazoadas em relação à construção da sua identidade. ${ }^{43}$

A privacidade pode ser definida como a capacidade de determinar o que o individuo deseja revelar e o quanto quer ser acessivel. ${ }^{44}$ Utilizar esse conceito para a claboração de norma acaba sendo difícil pois para isso dependerá do caso concreto, em que fatores como o grau de intimidade entre os envolvidos, o ambiente onde os relacionamentos ocorrem, as expectativas de cada um, entre outros, estão envolvidos.

Fica claro que a privacidade não é um conceito unitário. O professor Daniel Solove $^{4 \varsigma}$ argumenta que a privacidade não pode ser adequadamente definida pclo isolamento de um denominador comum em todas as miríades situações que entendemos haver uma violação da privacidade. Fle sugere um conceito bottom-up que focalize determinados problemas relacionados mas que não necessariamente partilham de um elemento comum. Existem muitos tipos de problemas de privacidade que. apesar de relacionados, distinguem-se significantemente.

A percepção de privacidade em determinado sistema jurídico em determinado momento histórico deve servir como base para controle de riscos legais que os sistemas de redes sociais enfrentam e das possibilidades de manifestação que os usuários possuem com amparo legal. Assim, deve ser decidido se as informações são livre e espontaneamente disponibilizadas a todos. indistintamente de ser seu observador um

4 "the right to be let alone" $\dot{e}$ expressão que ficou popular no caso Olmstead v. I/nited States, 277 U.S. 438. $478(1928)$

$\$ 2$ "the right 10 an inviolate personality", expressão usada por I ouis Brandeis e Samucl Warren em The Right to Privacy. artigo publicado na Harvard Law Review em 1890.

43 AGRF, Philip, op. cit.. p. 7.

is BELLOTTI. op. cit. p. 89.

4s SOLOVE, Daniel. Conceptualizing Privacy. Disponivel em: <http://law.shu.edu/faculty/fulltime faculty/soloveda/conceptprivacy.pdß>Acesso em 24 jul. 2004. p. I.093 
usuário credenciado ou-não, ou somente a usuários que tenham intimidade em determinado círculo social.

Faz-se também necessária a identificação de encarar a privacidade de forma objetiva ou subjetiva. Sc somente houvur violação da esfera da intimidade a partir do momento que um outro ser humano tem acesso a informações sensíveis, como opção religiosa, sexualidade, histórico de doenças, um sistema de inteligência artificial que receba tais informações, e esteja programado a não divulgá-las de modo algum, utilizando-as apenas com propósitos de levantamentos estatísticos. não infringiria a privacidade, de acordo com esta definição.

De qualquer forma, na busca de definições e respostas a indagações sobre a naturcza jurídica da privacidade, é necessário aceitar que, assim como a noção de subjetividadc, ela varia conforme o momento histórico vivido e, assim, não é apropriado que a lei engesse seu conceito. Entendida a privacidade como relacionada à informação que está disponivel a respeito de uma pessoa, deve-se reconhecer que, na sociedade da informação, existe tendência a uma maior dificuldade em controlar e identificar o que é público e privado.

Apesar da inexistência de diploma especifico sobre o tema, a proteção da privacidade é garantida pela Constituição Federal de 1988 ("CF88”) e legislação esparsa sobre o assunto. O Art- $5^{\circ} \mathrm{X}$, da CF88 diz que "são invioláveis a intimidade, a vida privada, a honru e a imagem das pessoas, assegurado o direito à indenizaçũo pelo dano material ou moral decorrente de sua violação" Assim, a intimidade configura-se, pcla redação constitucional, distinta do conccito de vida privada, honra e imagem das pessoas. Como esclarece José A fonso da Silva, a terminologia não é precisa e assim seu Curso de Direito Constitucional Positivo adota a expressão "direito à privacidade" em um sentido genérico e amplo.

Comentando o mesmo dispositivo constitucional, Celso Ribeiro Bastos ${ }^{46}$ afirma compreender a faculdade individual de obstar a intromissão de estranhos em sua vida privada e familiar e de impedir o acesso a informações sobre a privacidade de cada um e de evitar que scjam divulgadas informações sobre esta árua da manifestação existencial do ser humano.

A proteção à privacidade é considerada tanto um direito fundamental como um dircito da personalidade. São direitos de mesma essência, mas conforme Gilberto Haddad Jabur, o primeiro é ura proteção do individuo contra o arbítrio do Estado e o último pertence ao dircito privado. direcionado às relações entre particulares.

t6 BASTOS, Celso Ribeiro. Curso de Direilo Constitucional. São Paulo: Saraiva. 1989. v. 2. p. 63. 
Uma solução de arquitetura é proposta por Lawrence Lessig para os problemas de privacidade com base em duas premissas: 1) conferir a cada individuo um direito proprietário sobre suas informações pessoais; e 2) empregar protocolos de transmissão como o Privacy Preferences Project (P3P) ${ }^{47}$ que permite ao usuário controlar seu acesso a websites dependendo de suas preferências pré-estabelecidas de privacidade, de modo que, por exemplo, descontos em preços de mercadorias pudessem ser concedidos caso o usuário decidisse divulgar maiores informações pessoais.

A discussão que se coloca em torno do P3P e da solução de Lessig merece análise quanto ao caráter irrenunciável da privacidade enquanto direito fundamental. Caso prevaleça o entendimento de ser completamente irrenunciável, a negociação sugerida por Lessig seria nula e, portanto, permaneceria o website sujeito à responsabilidadc caso posteriormente o usuário, sentindo-se violado em sua privacidade por uma transação realizada, decida processá-lo. Os riscos ficam ainda mais agravados considerando-se a imprescritibilidade desse direito. ${ }^{48}$

Em 1980, a Organização para Cooperação Econômica e Desenvolvimento, OECD, estabeleceu linhas mestras de proteção à privacidade. ${ }^{49}$ Quanto ao Princípio da Participação Individual defendido pela OECD. que busca fornecer ao individuo o poder de obter a confirmação se dados a seu respeito estão inseridos em determinado banco de dados, de modo satisfatório, bem como providenciar sua retificação, merece destaque o instituto do habeas data previsto no art. $5^{\circ}$, I.XXII, da CF88 e regulado pela Lei n. 9.507. de 12.11.1997.

Ainda no campo de princípios gerais sobre tratamento legal da privacidade, é válido comentar também a nova disposição legal implementada no art. 21 do Código Civil, que estabelece que a vida privada da pessoa natural é inviolável, e o juiz, a requerimento do interessado, adotará as providências necessárias para impedir ou fazer cessar ato contrário a esta norma.

São, assim. diversos os recursos jurídicos e técnicos para o controle da privacidade. Apesar do interesse dos indivíduos em controlar a informação que chega a eles, manifesta por exemplo nos casos do telemarketing e do spam, existe um valor das informações compartilhadas em sociedade que pode ser perdido no caso de controle

4. O protocolo P3P nãu foi maciçamente adotado por uma série de fatores, como a falta de interesse dos consumidores e falta de um mecanismo de marketing para incentivar sua implementação $c$ uso. Entretanto, continua sendo uma alternativa técnica para lidar com a privacidade na Internet.

th Quanto a questionamentos sobre a elícácia das criativas propostas de Lessig, é válida a consulta a Beyond Lessig's Côs for Internet Privacy: Cyberspace Filters. Privacy-Control, and Fair Information Practices. de Paul Schwartz.

49 http://www.oecd.org/documenv/18/0,2340,en_2649_34255_1815186_1_1_1_1.00.html . 
total. $^{50}$ A economia capitalista e a sociedade livre dependem de trocas de informaçõ independentemente de prévia solicitação, como campanhas eleitorais, anúncios em outdoors, passeatas... os quais devem respeitar limites pré-estahelecidos. Im equilibrio pode ser atingido a partir do momento inicial em que é facultado receber informações adicionais conforme interesse do individuo.

Os benefícios da troca de informação. como diminuição de preços pela redução dos custos de transação a partir de um mercado mais transparente, ${ }^{51}$ são analisados por Kent Walker, que aponta, entre outros, para ampliação de acesso de informações e conveniência do atendimento customizado. Conforme informações pessoais são disponibilizadas o senso comunitário também é fortalecido, possibilitando assim a formação de elos de afinidade por intermédio de sistemas de comunicação telemáticos sem que a localização geográfica seja um ponto de partida ou uma coerção. ${ }^{52}$ A segurança é também aperfeiçoada pela maior confiabilidade das informações: números seriais de identificação em hardware e software podem ser utilizados para saber de onde vieram ataques a sistemas protegidos, e mesmo criação de vírus, como ocorreu no caso do autor do virus Melissa. ${ }^{\text {53 }}$

A anonímia, em situaçôes como essa, desestabilizaria a responsabilidade social e jurídica que pode ser atribuída em atos repreensíveis. A anonímia pode ter papel de importância no contexto de sistumas políticos repressores em que a liberdade de expressão não poderia de outra forma ser exercida, sob risco de retaliação. Mas, em situações ordenadas, não é um valor a ser defendido, de modo que o anonimato é vedado pela CF88, em seu artigo $5^{\circ}$ IV. A vedação constitucional busca assim, atribuir responsabilidade àqueles que exercem a liberdade de pensamento evitando os abusos que podem decorrer da impunidade facilitada pela ocultação. Os excessos devem ser sempre evitados: a demasiada preocupação com a privacidade. expressa na forma de normas rígidas, pode fazer com que outros valores sejam perdidos. A regulação apressada e sem reflexão pode causar o término de uma séric de atividades empreendedoras legitimas e inovadoras, e também prejudicar o livre fluxo de informações necessário para a promoção de objetivos individuais, comunitários e sociais.

so Esse excesso de controle é um fenómeno descrito como oversteer por Andrew Shapiro em The Contrai Revolution: How the Internet is Pulting Individuais in Charge and Changing the World We Knou: Basicamente, Shapiro alerta para os riscos que existem no controle absoluto das informações, que diminui os encontros aleatórios necessários para uma experiência comum, uma cola social, entré os cidadãos de uma democracia. Essa teoria é posteriormente desenvolvida por Cass Sunstein. em Republic.com.

31 MACEDO JR.. Ronaldo Porto, op. cit., p. 20.

52 LÉVY, op. cit., p. 20.

${ }_{33}$ WALKER. Kent. Where Everybody Knows Your Name: A Pragmatic Look at the Costs of Privacy and the Benefits of Information Exchange. Stanford Technology Law Review: Disponivel em: <http://stlr.edu/STLR/Article00 STLR_2>. Acesso em 08 jul. 2004. p. 17 
Como já observado, as tecnologias trazem aspectos tanto positivos como negativos. A atitude da sociedade perante assuntos de privacidade muda. conforme novas tecnologias apresentam benefícios, como a filmagem de ruas. A maior exposição das pessoas em ambientes públicos perante autoridades imperceptíveis contribui para a melhora na prestação de serviços públicos. especialmente quanto à redução da criminalidade. ${ }^{54}$ Além do peso imediato a ser suportado pela implantação desses sistemas, o que deve ser feito é uma análise dos danos que podem ocorrer caso o sistema suja violado por terceiros de má-fé ou saia de controle.

As reflexões sobre a natureza juridica da privacidade são necessárias para a sua proteção. A identificação do momento de sua violação é um dos pontos que requer maior definição: quando ocorre? No momento da coleta não autorizada? Quando um terceiro não autorizado obtém acesso aos dados? No processamento dos dados? Quando os resultados dos dados processados são publicados? Quando atitudes baseadas nos dados processados e publicados são tomadas?

Semelhantes questionamentos foram levantados pelo grupo de trabalho convocado pela OMPI para tratar da proteção dos bancos de dados: na ausência de uma autorização expressa por parte do titular do direito de autor, constituiria o aproveitamento de sua obra violação ao direito de autor ou somente a saída é quc a caracterizaria? Antônio Chaves relata que fora concluído "que a entrada (incluida a fixação na memória internu de um computador) deveria ser considerada uma reprodução, tanto mais que a saida não implica necessariamente em qualquer violação ao direito de autor e que a autorização necessária deveria ser solicitada por ocasião da entrada" Pode-se fazer uma analogia com relação ao momento em que pode ocorrer uma violação aos direitos de privacidade quando ocorre a mera inclusão dos dados em um sistema?

Nesse sentido, é necessário um alerta contra o Tecnopólio descrito por Neil Postman. A dependência excessiva das técnicas de estatística e mapeamento de perfil pode acabar rotulando os usuários a ponto de diminuir sua exposição a determinados conteúdos que o sistema de banco de dados entenda que não são de interesse pelo perfil analisado. Essa excessiva rotulagem diminuiria a liberdade dos cidadãos. ${ }^{55}$

\footnotetext{
54 A reportagem Olhos por loda parte publicada na Revista Veja, edição 1865, ano 37, n. 31, de 04.08.2004. relata a experiência de monitoramentn por câmeras instaladas nas ruas de Londres, Nova York, Washington, Paris. Berlim, Joinville, Recife, Suzeno, Belo Horizonte e Curitiba. Quanto à capital do Estado do Paraná, reporta que "houve protestos por parte da população assim que as fumadoras foram implantadas. Mas. com o passar do tempo, as pessoas se acostumaram com a presença delas"

5s O estudo promovido por Lada Adamic, Orkut Buyukkokten. e Eytan Adar, A Social Network Caught in the Web, disponivel em: <http://www.firstmonday.dk/issues/issuc8 6/adamic/ $>$, já traçava determinadas regras de fundamentalismo de acordo com a análise do Club Nexus.
} 
10. Direito à imagem

$\mathrm{O}$ art. $5^{\circ} \mathrm{X}$, da CF88 também protege expressamente o direito à imagem. que goza de autonomia no ordenamento jurídico nacional, existindo independentemente de outros direitos da personalidade. Sua indisponibilidade deve ser entendida de modo relativo, por ser possivel sua disposição parcial pelo indivíduo consentindo com a exposição, reprodução ou mesmo o comércio de sua imagem.

Os recursos das redes sociais em disponibilizar imagens de seus usuários ampliam a aplicação dessa exceção, o que se por um lado facilita a expressão da personalidade e interação socia:, implica também em potenciais violações ao direito de autor do fotógrafo quando suas obras são veiculadas sem autorização ${ }^{56} \mathrm{e}$, principalmente, agressões ao direito de imagem dos retratados, que podem não ter consentido em serem fotografados ou, em outra hipútese, apesar de consentirem em serem fotografados em determinada circunstância (por amigos, para que fosse guardada em álbum de fotografias e com moderada exposição), podem não-consentir em sua exposição a uma platéia indistinta e ampla como a que possui acesso à rede social. A esse respeito, Zulmar Antonio Fachin parafraseia o clássico trabalho de Adriano de Cupis:

O consentimento para uso da imagem. seja tácito ou expresso, gratuito ou mediante pagamento, tem limites. O Professor De Cupis estabelece hipóteses e limites para o uso da imagem: a) alguém permite ser retratada para deixar uma recordação a determinada pessoa: o retrato não pode rodar o mundo, pois a pessoa ao consentir que fosse tirada a fotografia, o fiz para um fim determinado e não para outros fins; b) se a pessoa consente em divulgar a própria imagem por um modo, sua imagem não pode ser divulgada por outro (ex.: consente tirar a foto para uma vitrine e não pode ser usada para cartão postal); c) se a pessua consente ter a imagem usada por determinado tempo, não pode a publicidade durar indefinidamente; d) se a pessoa consente divulgar a imagem perante certas pessoas, perante os outros resta inalterado o direito à imagem. ${ }^{57}$

Alím das situaçōes acima, cometem ato ilícito aqueles que promovem montagens e deformações de fotos que impliquem em dano, ainda que exclusivamente moral, conforme dispusto no art. 186 do Código Civil.

56 Observadas as limitações do art. 46 da Lei de Direitos Autorais.

57 FACHIN, Zulmar António. A Proteção Juridica da Imagem. Sāo Paulo: Celso Bastos Editor/Instituto Brasileiro de Dircito Constitucional, 1999. p. 95. 
Vale o alerta para os desenvolvedores de sistemas de redes sociais para que implementem mecanismos de denúncia aos administradores do sistema, de modo que aqueles que se sintam prejudicados com a publicação de imagens possam requerer a retirada da publicação das imagens.

\section{Proteção ao consumidor}

Questiona-se se as disposições de direito do consumidor seriam aplicáveis nas relações entre os prestadores desses serviços de redes sociais digitais e seus usuários brasileiros, o que implicaria em um tratamento jurídico diferenciado, geralmente com maior proteção ao usuário do que aquele previsto contratualmente nas cláusulas comumente encontradas nos contratos de adesão que os prestadores destes serviços pretendem impor.

Para ilustrar alguns aspectos desse tratamento diferenciado, vale mencionar princípios como o da inversão do ônus da prova, segundo o qual cabe ao fornecedor provar que as alegações dos consumidores são infundadas. Merece destaque também o dever de precaução e segurança, que aponta para uma obrigação em manter um sistema razoavelmente seguro para proteção de dados sensíveis. Proteções contra cláusulas abusivas também são garantidas, como a proibição de limitação de responsabilidade do fornecedor por vícios de qualquer natureza dos produtos e serviços.

Mesmo sendo geralmente uma relação que envolve prestador de serviço localizado fora do País, os prestadores destes serviços devem ter em mente o artigo primeiro do Código de Defesa do Consumidor, que dispõe que as normas de proteção e defesa do consumidor são de orcem pública e interesse social. A respeito, destaca-se que nosso ordenamento, através da Lei de Introdução ao Código Civil, determina a ineficácia de leis estrangeiras que ofendam a soberania nacional, a ordem pública e os bons costumes.

Além disso, a doutrina aponta para a interpretação de que nenhuma lei ou julgamento que de alguma forma prejudique ou restrinja os direitos dos consumidores deverá ser reconhecida no Brasil. Assim, mesmo se o contrato de prestação de serviços (inclusive freqüentemente disponibilizado somente no idioma inglês o que por si só já levanta controvérsias quanto à sua efetiva aplicação) contemplar a aplicabilidade de leis estrangeiras, tal provisão pode não ser aceita e o direito estrangeiro pode não ser aplicado se no caso concreto resultar em uma proteção menor que a do ('ódigo de Defesa do Consumidor brasileiro. 
Ainda, considerando-se que os serviços submetidos à legislação de proteção ao consumidor, conforme parágrafo $2^{\circ}$ do art. $3^{\circ}$ do ('ódigo de Defesa do Consumidor, devem ser prestados "mediante remuneração", é necessário ponderar se eventual gratuidade dos serviços de redes sociais digitais poderia ser apresentada como excludente à caracterização da relação de consumo.

Aparentemente a gratuidade dos serviços perante o usuário final não descaracteriza a relação de consumo. Este entendimento é elucidado nos casos em que o serviço de consumo é remunerado indiretamente por terceiros, como no caso do uso de transporte coletivo por idosos que, não obstante inexistir remuneração direta destes, o custo do serviço é repassado aos outros usuários. De forma análoga, entende-se haver a remuneração quando o consumidor fornece seus dados. que possuem valor econômico para a realização de estatísticas, aumento de tráfego implicando em maior visibilidade de anúncios, e outras modalidades típicas de modelos de negócios relacionados à internet. Em A Empresa na Velocidade do Pensamento, Bill Gates ilustra o conceito de "chegar primeiro ao mercado" valendo-se de exame de um renomado banco brasileiro altamente informatizado e que dispõe de complexa base de dados a respeito de seus clientes. "Esse histórico dos dados do cliente é um dos ativos mais valiosos do banco" segundo Gates.

Sendo uma relação de consumo, aplica-se o principio da solidariedade legal entre os causadores de danos ao consumidor de modo que, havendo mais de um autor desses danos. todos eles responderão solidariamente pela reparação. segundo o art. $7^{\circ}$, parágrafo único do Código de Defesa do Consumidor. Em mesmo sentido regula o Código Civil, no art. 942. O consumidor pode, assim, exigir de qualquer devedor a indenização pelo seu todo, sem necessariamente aguardar a discussão sobre a responsabilidade entre os devedores solidários.

A legislação do consumidor também traz regras especificas sobre privacidade, tema de grande destaque na atualidade. $O$ art. 43 estabelece que 0 consumidor terá acesso às informações existentes em cadastros, fichas, registros e dados pessoais e de consumo arquivados sobre ele, bem como sobre as suas respectivas fontes. Que os cadastros devem ser objetivos, claros, verdadeiros e em linguagem de fácil compreensão. não podendo conter informações negativas referentes a periodo superior a cinco anos. E que a abertura de cadastro, ficha, registro e dados pessoais e de consumo deverá ser comunicada por escrito ao consumidor, quando não solicitada por ele.

Ainda conforme o art. 43 do Código de Defesa do Consumidor, o consumidor sempre que encontrar inexatidão nos seus dados c cadastros poderá exigir sua imediata correção devendo o arquivista, $\mathrm{em}$ cinco dias úteis, comunicar a alteração aos eventuais destinatários das informações incorretas. Os bancos de dados e cadastros 
relativos a consumidores, os serviços de proteção ao crédito e congêneres são considerados entidades de caráter público. É assim possível o uso do habeas data para acessibilidade aos dados e certificar-se de que os dados serão corrigidos.

A inobservância a tais regras pode configurar crime contra relações de consumo, além de outros tipos de violações materiais e morais. Nesse sentido os arts. $72 \mathrm{e}$ 73 do Código de Defesa do Consumidor estabelecem infrações penais em relações de consumo: aquele que impede ou dificulta o acesso do consumidor às informações que dele constem em bancos de dados e aqueles que deixam de corrigir informações sobre consumidores em banco de dados que sabem ou deveriam saber inexatas estão sujeitos a detenção ou multa. Desse modo, é fundamental que a estrutura tecnológica permita aos administradores da rede social promover buscas e retificar dados com facilidade e baixos custos.

Em função disso, considerando-se a aplicabilidade das normas de proteção ao consumidor a relações envolvendo os prestadores dos serviços de redes sociais digitais, as questões relativas especialmente à proteção de dados devem ser consideradas.

Diante de dano alegado pelo usuário por uma ineficiência do sistema, que não permita a devida retificação de informação a seu respeito, ou não possua mecanismo de notificação aos administradores da rede sobre conduta abusiva de outros usuários que ofendam sua honra e integridade, do ponto de vista do direito do consumidor, não há significativa diferença no tratamento juridico aplicável a outros serviços, como os fotologs. weblogs e mesmo as homepages que contribuíram para a expansão da internet nos anos 90 .

Seguindo tendências jurisprudenciais recentes no campo da responsabilidade por intermediação de negócios consumer-lo-consumer, o prestador de serviços não responde, a princípio, pela intermediação. Entretanto, pode-se falar em uma obrigação em manter, na medida do razoável, um sistema eficiente de administração e controle para a correção de informações imprecisas e suspensão de contas de usuários que infrinjam os termos de uso, na medida que estes sejam denunciados aos administradores do sistema.

Conforme avança a tecnologia, é cada vez mais interessante considerar a viabilidade de implementação de sistemas de reconhecimento e autenticação dos dados de usuários cadastrados, evitando assim os clones (apelidados de "bogus" no Orkut e "fakesters" no Friendster) que năo raramente personificam celebridades ou criam perfis falsos e acompanhados de informações injuriosas, caluniosas ou que induzam terceiros a erros. Trata-se de aspecto a que os prestadores de serviços devem atentar, uma vez. que 
podem, inclusive, culminar em obrigações indenizatórias, sem considerar o envolvimento em eventuais ações penais.

\section{Conclusões}

Observa-se, quanto à responsabilidade solidária decorrente de comportamento dos usuários do sistema, uma tendência à analogia com as teorias sobre responsabilidade de provedores de acesso (Internet Service Providers) debatidas no fim dos anos 90 acerca de infração de marcas e direitos autorais. violação de direito à imagem, calúnia... entre outros. Fxistem, contudo. novos conflitos trazidos pelas redes sociais, especialmente aqueles ligados à privacidade e à difusão de informações pelos diversos círculos sociais simultancamente.

As redes sociais apresentam novas formas de interação social e um questionamento sobre os limites legais, contratuais e tecnológicos para a sua utilização. Pela sua natureza de rede, conforme maior sua utilização, maior poder possui para a atração de novos usuários, influenciando na análise de custo e bcnefício de estar ou-não cadastrado a um sistema de rede social.

A proteção a bancos de dados diferencia-se da proteção conferida à privacidade. Entretanto, sua regulação juridica é difícil por existir uma pluralidade de concepções acerca dos espaços públicos e privados, uma dilerente valoração de custo c benefício dos usuários de redes sociais, que se transforma em uma colaboração dos próprios individuos para uma maior exposição de sua vida particular a público. A libcrdade de escolha ¿ um valor que deve ser preservado, entretanto evitando a comoditização da privacidade, caso entendida como um valor constitucional indisponivel.

A lei não deve impor concepções sobre o que é público e o que é privado, mas sim oferecer mecanismos para aqueles que desejam proteger sua esfera intima e fornecer meios de reparação caso essa seja devassada. Sendo ferramentas que permitem violações de proporções antes desconhecidas. as redes sociais devem estar atentas ¿ responsáveis para orientar seus usuários sobre os riscos envolvidos e providenciar mecanismos tecnológicos e contratuais buscando a máxima proteção e menor oportunidade de realização de práticas abusivas através de seus sistemas. Os riscos aprescntados diante da operação de redes sociais são considerávcis, dada a subjetividade do conccito de privacidade. Para bem gerenciar os riscos do negócio, a lccnologia do sistema de rede social deve possibilitar tornar privada determinada informação a determinado grupo de pessoas ou a um grupo indistinto. Assim, combinar tecnologia e dircito é essencial. Para isso, os termos de uso e políticas de privacidade são importantes, 
devendo-se ressaltar que o Direito brasileiro não aceita negociação particular sobre provisões de matéria pública e cogente, existindo limitação à liberdade contratual que deve scr considerada.

A construção colaborativa da regulação das redes sociais inclui os usuários, desenvolvedores destes sistemas e, principalmente, legisladores que estabelecerão limites legais mínimos para atingir um equilíbrio apropriado e saudável entre o público e o privado.

São Paulo, dczembro de 2005.

\section{Referências}

AGRE, Philip; ROTEMBERG, Marc (Org.). Tecnhology and Privacy: The New Landscape. London: The MIT Press, 1998.

ARATA Jr., Sciiti. O Processo de Regulação do Comércio Eletrônico na Internet: Critérios e Conseqüências. 2000. 76 f. Relatório de Iniciação Cientifica apresentado para Fundação de Amparo à Pesquisa do Estado de São Paulo - FAPESP, Universidade de São Paulo, 2000.

O Equilíbrio do Poder na Regulação da Internet. Revisıa da Associação Brasileira da Propriedade Intelectual, São Paulo, n. 53, p. 03-17, jul.-ago. 2001.

Enhancing the Digital Democracy Architecturc. In: $32^{\text {nd }}$ ISC Symposium, 2002. Sankt Gallen.

Dimensões Jurídicas da Governança da Internet. 2003. Artigo vencedor do $2^{\circ}$ prêmio. categoria Direito da Informática, no 2" Concurso de Monografias da ABDI. In: 17\% Seminário Internacional da ABDI.

ARENDT, Hannah. A Condição Humana. 10. ed. Rio de Janeiro: Forense Universitária, 2004.

ALVIM, Arruda [et al]. Código do Consumidor Comentado. 2. ed. São Paulo: Editora Revista dos Tribunais, 1995.

BASTUS, Celso Ribeiro; MARTINS, Ives Gandra. Comentários à Constituiçũo do Brasil: promulgada em 5 de outubro de 1988. São Paulo: Saraiva, 1989.

BITTAR, Carlos Alberto; BITTAR FILHO, Carlos Alberto. Tutela dos direitos da personalidade e dos direitos autorais nas atividades empresariais. I ed. São Paulo: Editora Revista dos Tribunais, 1993. 
BOYD, Danah. Faceted Id/Entity: Managing representation in a digital world. Disponivel em: <http://smg.media.mit.edu/people/danah/thesis/> Acesso em 14.07.2004.

CHAVES, António. Direitos Autorais na Computaçào de Dados: software, circuitos integrados, videojogos, embalagem criativa, duração dos direitos conexos. 1. ed. São Paulo: I.'Tr, 1996.

COELHO, Marcelo. A estrutura viscosa do Orkut. Folha de São Paulo. Disponivel em: $<$ http://wwwl.folha.uol.com.br/fsp/ilustrad/fq3006200414.htm> Acesso em 07.07.2004.

COMPARATO, Fábio Konder. A Afirmação Histórica dos Direitos Humanos. 3. ed. São Paulo: Saraiva. 2003.

FACHIN, Zulmar António. A Proteção Juridica da Imagem. São Paulo: Celso Bastos Editor: Instituto Brasileiro de Direito Constitucional, 1999.

GUERRA, Sidney César Silva. O Direito à Privacidade na Imternet: uma discussão da esfera privada no mundo globalizado. Rio de Janeiro: América Juridica, 2004.

HEYMANN, Paul. Distributed Social Network Protocol. Disponivel em $<$ http://www.cs.duke.edu/ -pbh/downloads/dsnp-paper.pdf $>$ Acesso em 24.07.2004.

JABUR, Gilberto Haddad. Liberdade de Pensamento e Direito à Vida Privadu. 1. ed. São Paulo: RT, 2000.

JORDAN. Tim. Cyberpower: The Culture and Politics of Cyberspace and the Internet. 1. ed. London: Routledge, 1999.

KEUNECKE, Karla. Das Bases de Dados - Proteção Juridica no Âmbito da Propriedade Intelectual. Revista da Associação Brasileira da Propriedade Intelectual, São Paulo, n. 57, p. 48-55, mar.-abr. 2002.

LEONARD, Andrew. You ure who you know. Salon.com. Disponivel em: <http://www.salon.com/tech/feature/2004/06/15/social soltware_one/> Acesso em 16.07.2004.

LESSIG. Lawrence. Code and Other Laws of (yberspace. 1. ed. New York: Basic Books. 1999.

LIMBERGER, Têmis. As informações armazenadas pela instituição bancária e o direito à intimidade do cliente. Revista de Direito do Consumidor. São Paulo, n. 43, p. 273, jul./set. 2002.

MACFDO JR., Ronaldo Porto. Privacidade. Mercado e Informação. Rúvista de Direito do Consumidor: São Paulo. n. 31, p. 13. jul./set. 1999.

MESSA. Eric Eroi. Cuneça a era do sofrware social. Disponivel cm: <http:/iwww.dcomercio.com.br/noticias online/339640.htm> Acesso em 24.07.2004. 
MIESZKOWSKI, Katharine. Faking out Friendster. Salon.com. Disponível em: <http://www.salon.com/tech/feature/2003/08/14/fakesters/print.html Acesso cm 14.07.2004.

MORAES, Alexandre de. Constituiçăo do Brasil interprelada e legislą̧âu cunstilucionnal. 2. cd. São Paulo: Atlas, 2003.

PÓSTER, Mark. CyberDemocracy: Internet and the Public Sphere. Disponivel em $<$ http://www.hnet.uci.edu/mposter/writings/democ.html > Acesso em 14.07.2004.

POSTMAN, Neil. Technopoly- The Surrender of Culture to Technology. I. ed. New York: Vintage, 2000. REALE, Miguel. Fundamentos do Direito. 3. ed. São Paulo: RT, 1998.

Teoria Tridimensionul do Direito. 1. ed. São Paulo: 1:ditora Saraiva, 1968. RHEINGOLD, Howard. A Comunidade Virtual. 1. ed. Lisboa: Gradiva, 1996.

SHAPIRO, Andrew. The Contrai Revolution: How the Internet is Putting Individuais in Charge and Changing the World We Know. 1. ed. New York: Public Affairs, 1999.

SHIRKY. Clay. Social Software and the Politics of Groups. Disponivel em <http://www.shirky.com/writings/groupjpolitics.html> Acesso em 24.07.2004

SILVA, José Afonso da. Curso de Direito Constitucional Positivo. 12. ed. São Paulo: Malheiros Fditores. 1996.

SILVEIRA, Clovis. Bancos de Dados Originais e Não-Originais. Revista da Associação Brasileira da Propriedade Intelectual, São Paulo, n. 69, p. 31-35, mar./abr. 2004.

SOLOVE, Daniel J. Conceptualizing Privacy. Disponivel em

$<$ http://law.shu.edu/faculty/fulltime_faculty/soloveda/conceptjprivacy.pdf $>$ Acesso em 24.07.2004.

SUNSTEIN, Cass. Republic.com. I. ed. New Jersey: Princeton University Press, 2001.

SCHWARTZ, Paul M. Beyond Lessig 's Code for Internet Privacy: Cyberspace Filters. PrivacyControl, and Fair Information Practices. Disponivel em:

<http://www.paulschwartz.net/pdf/Schwartz_final.pdr> Acesso em 24.07.2004.

TUGNOLLI, Cláudio Júlio. Domingo Legal Promotora Processa Gugu por Danos Morais e Pede R\$750 mil. Consultor Juridico. Disponivel em

$<$ http://conjur.uol.com.br/staticitextos/246975,!.shtml\% Acesso em 24.07.2004

WALKER. Kent. Where Everybody Kurows Your Name: A Pragmatic Look at the Costs of Privacy and the Benefits of Information Exchange. Stanford Technology Law Review. Disponivel em: <http://stlr.stanford.edu/STL.R/Articles/00_STLR_2> Acesso em 08.07.2004. 
WEBSTER, Frank (Org.). Theories of the Infurmation Society. I. ed. London: Routledge, 1995.

WHIT TL, David. Cyherspace: the Human Dimension. I. ed. New York: W. H. Freeman and Company, 1997. 